\title{
VICENTE ALEIXANDRE CON FEDERICO GARCÍA LORCA Y DÁMASO ALONSO
}

\author{
Vicente Granados Palomares \\ UNED \\ vgranados@flog.uned.es
}

\section{RESUMEN}

Se describe el influjo de Rubén Darío en el origen poético de Vicente Aleixandre, Federico García Lorca y Dámaso Alonso y la coincidencia de la fecha (verano de 1917), cuando cabría esperar que fuera el impulsor de ese origen común Juan Ramón Jiménez ya que había publicado en ese mismo año su magistral y revolucionario Diario de un poeta reciencasado. Pero no solo consideran a Darío como el maestro que les inclinó a ser poetas, sino que su admiración duró siempre.

La amistad de los tres tuvo consecuencias literarias de diversa índole. El voto de Dámaso Alonso fue decisivo para que Aleixandre ganara el Premio Nacional de Literatura. Para ganar ese premio, el poeta tuvo que atenuar su surrealismo. Es impensable que lo hubiera obtenido con Espadas como labios o con Pasión de la Tierra. A partir de entonces fue acogido entre los grandes, como lo demuestra la excelente y calurosa reseña que le dedicó Pedro Salinas.

En torno a Lorca se crea una mitificación en la que Aleixandre y Alonso no son ajenos. El primero dio título - casi medio siglo antes de ser publicados- a los Sonetos del amor oscuro. Y fue el primero que reseñó en forma de carta el Romancero gitano, donde expone su concepto de poeta aplicado a Lorca, quintaesencia del mismo para Aleixandre, concepto que repite en la evocación de 1937, «Federico».

Lorca admiró sin reservas a Aleixandre como demostró en varias ocasiones: citas, declaraciones, referencias epistolares. 
Alonso también se encuentra entre los que resaltaron la figura deslumbrante de Lorca en el 27, especialmente en el ensayo definitorio de aquel grupo, «Una generación poética» (1948).

La relación entre Lorca y Alonso pudo tener reflejo en Hijos de la ira, pues su autor tuvo el privilegio de oír varias composiciones en 1929 de Poeta en Nueva York, leídas por Lorca conforme las escribía.

Palabras Clave: Amistad. Grupo poético. Guerra civil. Influencias. 27.

\section{ABSTRACT}

The influence of Rubén Darío in the poetic origin of Vicente Aleixandre, Federico García Lorca and Dámaso Alonso and the coincidence of the date (summer 1917) is described, when it would be expected to be the driver of that common origin, Juan Ramón Jiménez as his masterful and revolutionary Diario de un poeta reciencasado there was published in the same year. But Darío is not only considered as the master who tipped them to be poets but admiration lasted forever.

The friendship of the three had literary consequences of various natures. Dámaso Alonso's vote was decisive for Aleixandre won the National Literature Prize. To win this prize, the poet had to mitigate its surrealism. It is unthinkable that they have been obtained with Espadas como labios or Pasión de la Tierra. Thereafter it was welcomed among large, as evidenced by the excellent and warm review dedicated by Pedro Salinas.

Around Lorca mystification is created where Aleixandre and Alonso are no outsiders. The first gave title - almost half a century before being published - to the Sonetos del amor oscuro. And he was the first to outline as letter Romancero gitano, which explains his concept of poet applied to Lorca, quintessential for Aleixandre, concept that repeated evocation of 1937 , «Federico».

Lorca admired unreservedly to Aleixandre as demonstrated on several occasions: appointments, statements, epistolary references.

Alonso also is among those who highlighted the dazzling figure of Lorca at 27, especially in the defining essay of that group, «Una generación poética» (1948).

The relationship between Lorca and Alonso could be reflected in Hijos de la ira, because the author was privileged to hear several compositions in 1929 of Poeta en Nueva York, read by Lorca according he wrote.

KeY wORDs: Friendship. Poetic group. Civil war. Influences. 27.

\section{Jorge GuILlÉn: Amigos. NADIE MÁs. El RESTO ES SELVA.}

«Generación de la amistad» es uno de los apelativos con que se ha bautizado al 27, aquel grupo en el que Guillén incluía a Pedro Salinas, él mismo, Gerardo Diego, Federico García Lorca, Vicente Aleixandre, Dámaso Alonso, Emilio Prados, Rafael Alberti, Luis Cernuda y Manuel Altolaguirre. Nómina problemática, a la que me he referido ${ }^{1}$.

${ }^{1}$ Granados, Vicente (2013): «Algunos componentes del 27. El problema de su nómina», en Literatura española (1930-1939), 2. reed., Madrid, Editorial Universitaria Ramón Areces, pp. 238-240. 
Pero si definir el conjunto es muy difícil, la publicación de cartas y documentos de los miembros y del círculo del 27 ha echado por tierra el marbete «de la amistad». Hubo también amistades inalterables entre algunos, como fue el caso de Salinas y Guillén. He elegido para este homenaje a Miguel Ángel Pérez Priego y José María Lucas de Dios la de tres poetas inmensos, cuya lealtad mutua superó el sufrimiento y la tragedia.

Los tres nacen en 1898 (Vicente, Federico y Dámaso: Sevilla, Fuentevaqueros y Madrid: 26 de abril, 5 de junio, 22 de octubre). Sus vivencias infantiles y juveniles son diferentes. Y los paisajes, también. Pero pronto empiezan a coincidir en algo fundamental, alguien clave: Rubén Darío ${ }^{2}$. Dámaso declara que en seguida se contagia del entusiasmo por la obra de Darío, muerto en 1916. «Como yo no había tenido nunca con la poesía de autores de aquellos años» ${ }^{3}$, dice Dámaso. Y Vicente reconoció siempre: «Rubén Darío fue el primer gran poeta que tuve entre las manos [...] la familiaridad del verso, con su materia verbal, el número y el ritmo, ese fluidísimo conocimiento que ha de estar en la sangre del poeta, creo que a él se lo debo más que a nadie» ${ }^{4}$. La relación Darío-Aleixandre trascendió los años juveniles del poeta sevillano ${ }^{5}$. Con respecto a Lorca, recordemos que «Canción / Ensueño y confusión» ${ }^{6}$, que es tal vez su primer poema es rubendariano por los cuatro costados. Y su libro de prosas, Impresiones y Paisajes está en deuda con Los raros. Muchos años después, en Buenos Aires, Lorca reclama la atención sobre Rubén, en el célebre al alimón con Pablo Neruda ${ }^{7}$. Resulta entonces que el denominador común de los tres poetas es Rubén Darío. Ya es un tópico citar que fue Dámaso Alonso quien le dio a conocer a Aleixandre la poesía de Darío durante el verano de 1917 en las Navas del Marqués. Pero no son tópicas las palabras con las que Vicente recuerda su impresión sobre el nicaragüense:

Dos muchachos de la misma edad, caminando bajo los pinos variantes, perdida la noción del paisaje fugaz, sintiendo el hontanar perdurable y refiriéndose a él como a un centro absoluto. La poesía era salvadora del tiempo — se dirían—, era una fijación estrellada de luces redentoras. Sí: el supremo éxtasis ${ }^{8}$.

Pasado el tiempo, el voto de Dámaso Alonso fue clave para que Vicente Aleixandre — harto de ser un excelente poeta joven, poco leído— ganara el Premio Nacional de Literatura. Para eso tuvo que sacrificar el volcánico surrealismo de Pasión de la Tierra y

${ }^{2}$ Resulta extraño que su ídolo inicial no fuera Juan Ramón Jiménez, que publica su revolucionario y crucial Diario de un poeta reciencasado también en 1917, con fulminante éxito que se tradujo en varias ediciones en el mismo año, algo insólito en poesía. Sin embargo, JRJ escribió sobre los tres sus respectivas «caricaturas»: Dámaso Alonso y Federico García Lorca en 1928 y la de Vicente Aleixandre, dos años después. Recogidas luego en Jiménez, Juan Ramón (1942): Españoles de tres mundos, Buenos Aires, Editorial Losada, pp. 118-119, 134-135, 147-148, respectivamente.

3 Alonso, Dámaso: Antología de nuestro monstruo mundo (1985), coordinada por Margarita Smerdou Altolaguirre, Madrid, Cátedra, p. 12.

${ }^{4}$ Cano, José Luis (1981): Vicente Aleixandre, Madrid, Ministerio de Cultura, p. 8.

${ }_{5}^{5}$ Granados, Vicente (1988): «Vicente Aleixandre en el centenario de Azul...», Revista de Occidente, 8687 , pp. $144-155$.

${ }_{6}^{6}$ El manuscrito está fechado el 29 de junio de 1917.

7 Lorca y Neruda pronunciaron este discurso en el Pen Club de Buenos Aires (20-11-1933). Es una de las más vehementes reivindicaciones del nicaragüense por parte de los poetas de la época.

${ }^{8}$ Aleixandre, Vicente (1958): Los encuentros, Madrid, Guadarrama, p. 95. 
Espadas como labios ${ }^{9}$, que mereció una antológica reseña del propio Dámaso ${ }^{10}:$ «Qué libro! :Qué libro tan agrio, revuelto, duro, supurado, veteado, lívido, rosado, beatífico, arcangélico! ¡Qué gran masa, qué gran torrente de poesía (...), mezcla de dolor y de sarcasmo y de ternura y delicadeza!» Como era de esperar destaca hasta el punto de transcribirlas dos composiciones inolvidables en la obra aleixandrina: «El vals» $\mathrm{y}$ «Nacimiento último», esta última en su totalidad.

El Premio Nacional lo ganaría en diciembre de 1933 con un jurado compuesto por Manuel Machado, Gerardo Diego y Dámaso Alonso. La obra ganadora, La destrucción o el amor. La concesión del premio le da a Aleixandre — según confesión propia— «la agridulce sensación de que había dejado de ser un poeta joven». Y Pedro Salinas, reconociendo la marcada personalidad de Aleixandre en Ámbito y Espadas como labios -Pasión de la Tierra permanecía inédito-, afirma que nuestro poeta «hasta la aparición del libro La destrucción o el amor era estimado por un reducido círculo como una segura fuerza del porvenir lírico español» ${ }^{11}$. Aleixandre se incorpora así a un grupo consolidado, y entre los que quedan fuera por entonces está Luis Cernuda, que también se presentó y obtuvo un accésit. La historia un tanto rocambolesca de aquel premio se puede ver en Rivero Taravillo ${ }^{12}$. Lo que queda claro es que fue Dámaso Alonso el artífice del premio de su amigo. Amistad que llega hasta el final. La última tarjeta postal que escribe Vicente (28-8-84) dice: «Puedo escribirte, pero no leer manuscritos, salvo, espero, tu clarísima letra».

Lorca fue y sigue siendo el mito del 27. Jorge Guillén lo evoca así: «Junto al poeta - y no solo en su poesía - se respiraba un aura que él iluminaba con su propia luz. Entonces no hacía ni frío del invierno ni calor del verano: «hacía Federico». La exposición Signos de amistad. La colección de Federico García Lorca y la publicación de su catálogo dio a conocer la enorme red de amistad que rodeó al poeta granadino ${ }^{13}$. A la mitificación contribuyeron muy eficazmente Dámaso y Vicente. Conviene insistir también en la buena amistad que los unió, y vaya como dato esta referencia. Al dorso de una fotografía (a las puertas del Parque del Retiro, en abril de 1931), Lorca escribió: «Dentro de la verja canta una fuente/ que oyen Dámaso y Vicente./ Con el libro y el sombrero/ Dámaso ríe el primero/y Vicente con su pañuelo/ sueña un paisaje de hielo./Pero yo que soy Federico/ muevo en su honor alas y pico» ${ }^{14}$.

Lorca y Dámaso están juntos en proyectos desde 1925. Pero es en 1927 (27 de enero) cuando firman con Jorge Guillén, Pedro Salinas, Gerardo Diego y Rafael Alberti la carta para preparar el homenaje a Góngora, hecho clave que aúna a la generación o grupo del 27. Se trata de una carta circular, cuyos destinatarios fueron - entre otros- Melchor Fernández Almagro y Benjamín Jarnés. Después siguen coincidiendo. Juntos los vemos

\footnotetext{
9 Véase en Granados, Vicente (1977): La poesía de Vicente Aleixandre (Formación y evolución), Madrid, Cupsa Editorial. Entonces llamé al fenómeno «surrealismo en declive».

${ }^{10}$ Alonso, Dámaso (1932): «Vicente Aleixandre. Espadas como labios», Revista de Occidente, CXIV, pp. 322-333.

${ }^{11}$ Salinas, Pedro (1935): «Nueva poesía (sobre La destrucción o el amor)», Índice Literario, V, pp. 93-100.

12 Rivero Taravillo, Antonio (2008): Luis Cernuda/ Años españoles (1902-1938), Barcelona, Tusquets Editores, pp. 284-287.

${ }^{13}$ El catálogo lleva el mismo título que la exposición, que se pudo ver en Granada (6-11-1997 - 8-1-1998) y Madrid (febrero-marzo de 1998). Madrid, Publicaciones de la Residencia de Estudiantes, 1991.

${ }_{14}$ Poco reproducida, la fotografía está recogida en García-Posada, Miguel (1999): Acelerado sueño/ Memoria de los poetas del 27, Madrid, Espasa Fórum, pp. 96-97.
} 
en Sevilla para homenajear a Góngora, firman tarjetas postales. Ya en la posguerra y después del intento fallido de un acercamiento al 27 en el exilio ${ }^{15}$, Dámaso escribe el interesante ensayo «Una generación poética (1920-1936) ${ }^{16}$ en 1948. Allí dice: «Federico, mi príncipe muerto [...] Tú tenías como ninguno la risa alegre, la gracia genuina que a todos impregna [...]; la sal de España se había concentrado en ti». Estas cálidas palabras provocaron los agrios versos de Luis Cernuda en su poema «Otra vez, con sentimiento», escrito en México entre octubre y noviembre de 1960: «¿Príncipe tú de un sapo? ¿No les basta/ A tus compatriotas haberte asesinado?/ Ahora la estupidez sucede al crimen».

La amistad entre Vicente y Federico data también de los albores del 27. El 7 de septiembre de 1928, Aleixandre acusa recibo de su ejemplar dedicado del Romancero gitano. Se trata de uno de los primeros análisis de la apoteósica obra lorquiana. La carta es excepcional por su valor intrínseco — selecciona y comenta versos inolvidables del Romancero-y analiza el concepto«poeta»:

Esto de enajenarse uno en el poeta, de sentirse uno fuera de sí, en él, creo que no ocurre en la poesía de hoy con nadie con la intensidad que contigo. A fuerza de intensidad es aniquiladora: desplaza toda sensación de ser autónomo para trocar al lector en pura y pasiva lira, frenética de resonancias, en las manos del poeta creador ${ }^{17}$.

Luego vienen varias tarjetas dirigidas a Jorge Guillén, Mathilde Pomès, en las que figuran las firmas de Vicente y Federico. Son tarjetas importantes porque reúnen las firmas del 27. Hay bromas. El humor es una de las claves del grupo. Así, Luis Cernuda firma Ludwig en la postal a Guillén, Gerardo Diego se convierte en Gararda Diaga en la tarjeta a Mathilde, musa del 27. En esta se lee como despedida: «Desde casa de Vicente/ mil abrazos a Mathilde van, ausente». Nadie la firma, pero la letra es de Lorca. Sito Alba data esta misiva el 18 de diciembre de 1931. La relación de firmantes me parece importante: Gararda Diaga (poeta humano)/ Vicente/«Vicente Espinel» «o El Hombre/ Que más Postales escribía a Matilde», Manolo/ patas de lobo (Manuel Altolaguirre) y Carlitos Transparente, que no es otro que Carlos Morla Lynch.

En junio de 1932, Federico le escribe a su amigo Carlos Martínez-Barbeito:

Ayer llevé a mi querido Vicente Aleixandre otra vez al sanatorio y mañana le extirpan un riñón. Es una operación grave. Cuando se despidió de mí, se echó a llorar de un modo que no podía consolarlo. Yo quise ser fuerte, pero no pude. El médico me ha dicho que corre peligro y yo estoy desolado. La vida es injusta con él, y a medida que tiene más dolor, es más bueno y más dulce y más profundo ${ }^{18}$.

${ }^{15}$ Fue en el verano de 1948 y en Middlebury College estuvo el foco principal pero el intento fracasó. Se puede ver — entre la abundante bibliografía sobre el particular — Salinas, Pedro/Guillén, Jorge (1992): Correspondencia (1923-1951), Barcelona, Tusquets Editores. La edición, introducción y notas son de Andrés Soria Olmedo. Son importantes las cartas de Cernuda, Luis (2003): Epistolario (1924-1963), Madrid, Publicaciones de la Residencia de Estudiantes. La edición es de James Valender. Para este problema son clave sobre todo las cartas 484, 485, 486 y especialmente la 487, pp. 453-459. En esta última Cernuda rompe radical y definitivamente con Dámaso Alonso. Es importantísimo el libro de TERUEL, José (2013): Los años norteamericanos de Luis Cernuda, Valencia, Pre-Textos.

16 Alonso, Dámaso (1965): Poetas españoles contemporáneos, $3^{\mathrm{a}}$ ed., Madrid, Gredos, pp. 155-177.

17 Aleixandre, Vicente (2001): Correspondencia a la Generación del 27 (1928-1984), Madrid, Castalia, p. 54. La edición es de Irma Emiliozzi.

${ }_{18}$ García Lorca, Federico (1997): Epistolario completo, Madrid, Cátedra, p. 739. Editores A.A. Anderson y C. Maurer, 
Aleixandre supo corresponder. En el número VII de la revista Hora de España, mes de julio de 1937, publicó una semblanza de Lorca titulada «Federico», aunque salió en junio en El mono azul, menos conocida, pues la primera es —en palabras de Waldo Frank- «el mayor esfuerzo literario que ha salido de cualquier guerra». Por lo que se refiere al retrato, consideré hace tiempo que Vicente Aleixandre es uno de los grandes prosistas del $27^{19}$ y un magnífico cultivador del retrato literario en sus distintas modalidades, especialmente en la evocación y el encuentro. Vicente debió tener en alta estima su evocación por varios motivos. Se trata del célebre escrito que aparece como epílogo de las Obras Completas de Lorca en Aguilar. Se conserva una carta de Aleixandre a Isabel García Lorca (21-2-1954), relacionada con las Obras Completas citadas y de la que entresaco algunos datos: «En la plana o portada, se pone «Prólogo de Jorge Guillén», debe añadir debajo: «Epílogo de Vicente Aleixandre». Y advierte: «Luego al llegar al final mi texto, debe indicarse lo del Epílogo en la portadilla que lo anteceda. Por eso va indicado en mi texto. El título de este es «Federico». Y formula una petición: «Te agradeceré indiques al editor no suprima la fecha (1937) que he puesto al pie de mi original. Esto es importante». Vicente recordaba de esta manera la primera publicación de su evocación al tiempo que burlaba la torpe censura franquista, pues evidentemente no podía referirse a las revistas republicanas, malditas entonces. Pero también es importante porque se trata del primer escrito del conjunto que luego publicaría con tanto éxito: Los encuentros. El poeta narra la última visita de Federico a su casa de Velintonia en julio de 1936 donde le lee sus Sonetos del amor oscuro. Pocos días después Lorca tomará el tren de Granada, pero en el verano de 1937 Vicente no sabe si se han salvado los originales en medio de tanta destrucción, y termina:

Si esa obra no se ha perdido, si para honor de la poesía española y deleite de las generaciones hasta la consumación de la lengua, se conservan en alguna parte los originales, cuántos habrá que sepan, que aprendan y conozcan la capacidad extraordinaria, la hondura y la calidad sin par del corazón de su poeta ${ }^{20}$.

Aleixandre fue el primero que bautizó el conjunto con el discutido«oscuro», que luego se ha mantenido a pesar de una corriente contraria. Gibson da pormenorizada cuenta de esta polémica ${ }^{21}$.

Bondad, dulzura, profundidad señaló Lorca en Aleixandre cuando a este le atenazaba el dolor. Capacidad extraordinaria, hondura y calidad sin par del corazón definió Aleixandre cuando ya la tierra había cubierto a Lorca. Yo veo, sin embargo, en el poema que Aleixandre dedica a Lorca y que titula «El enterrado» la clave particular de lo que supuso la guerra civil en la relación amistosa. Por eso el análisis que llevé a cabo del mismo lo llamé «Olvidar es morir» ${ }^{22}$. Pocos años después desapareció Aleixandre, y el alejandrino que cerraba el poema lo sigue cerrando como un engarce con el futuro de todos:

¡Ah, corazón constante que, inmortal tú, retumbas!

\footnotetext{
${ }^{19}$ Granados, Vicente (1978): «Dos notas sobre el prosista Vicente Aleixandre», Ínsula, 374-375, p. 24.

${ }^{20}$ Aleixandre, Vicente (1937) «Federico», Hora de España, VII, pp. 139-141.

${ }^{21}$ Gibson, Ian (2009): Lorca y el mundo gay, Madrid, Planeta, pp. 15-42, especialmente.

${ }_{22}$ Granados, Vicente (1979): «Olvidar es morir/(Análisis de «El enterrado»)», Cuadernos Hispanoamericanos, 352-354, pp. 415-433.
} 
Aleixandre escribe su poema «El enterrado» con la última pretensión del enunciado:

Corazón constante

inmortal tú

retumbas

Volvamos al comienzo:

Buen amigo, en la tarde completa estoy sintiendo

tu vivir. Dime. Escucho. Yo te escucho, acabado.

Los tres núcleos diferenciados

buen amigo

en la tarde completa

estoy sintiendo

se corresponden exactamente con el final:

corazón constante

inmortal tú

retumbas.

Pasados los años, recordé este poema en una sesión sobre la Memoria histórica ${ }^{23}$ porque contiene las claves ideológicas del movimiento que se llamó así.

La amistad entre Federico y Vicente toma profundo sentido a partir del periodo republicano. Lorca, que tanto seleccionó las citas de Poeta en Nueva York, eligió una de Aleixandre para «Danza de la muerte», el poema que refleja con mayor nitidez la quiebra de la Bolsa neoyorquina. Se trata de un poema-crónica, datado en diciembre de 1929. «Danza de la muerte» es un poema desgarrador:

Era el momento de las cosas secas, de la espiga en el ojo y el gato laminado.

Era la gran reunión de los animales muertos, traspasados por las espadas de la luz.

Que ya las cobras silbarán por los últimos pisos, que ya las ortigas estremecerán patios y terrazas, que ya la Bolsa será una pirámide de musgo, que ya vendrán lianas después de los fusiles y muy pronto, muy pronto, muy pronto.

¡Ay, Wall Street;

¿Qué cita Lorca de Aleixandre a la cabeza de su poema? Pues unos versos impregnados de morbidez, pertenecientes al poema «Vida», de La destrucción o el amor, editada en 1935. Lorca extrajo los dos versos iniciales:

${ }^{23}$ Granados, Vicente (2006): «Olvidar es morir»: El 27 y la Memoria histórica, UNED de Mérida, 10-12 de julio, en el Curso Literatura y Memoria histórica. Amplié el análisis en otro contexto: Granados, Vicente (2009): «Memoria histórica y Segunda República», UNED de Mérida, 6-8 de julio, en el Curso Letras y Espectáculos en la Segunda República. Ambos cursos fueron dirigidos por Miguel Ángel Pérez Priego. 
Un pájaro de papel en el pecho

dice que el tiempo de los besos no ha llegado.

Años de amistad. En febrero de 1936 vemos en una fotografía a Federico entre María Teresa León y Vicente Aleixandre ${ }^{24}$. Se celebraba una comida en honor de los periodistas argentinos. Vicente está pletórico, Lorca escucha con cierta ironía a una persona que está de espaldas. María Teresa observa. En una entrevista concedida a Alberto F. Rivas, publicada en La Razón (Buenos Aires, 21/ X/1933) ${ }^{25}$, Lorca declara: «En España tenemos un valor: don Vicente Aleixandre, uno de los mejores poetas del momento, que frecuentemente escribe con duende [...] Conversar con él es lamentar la despedida, es recibir mucho bien en el corazón, y llenarse de ventura y de paz». Recordemos que Lorca había dado la primera lectura de su conferencia «Juego y Teoría del duende» en la Sociedad de Amigos del Arte, en Buenos Aires, un día antes de la entrevista que acabo de citar, en la que precisamente no habló de Aleixandre. En 1932 Aleixandre dedicó a Lorca la segunda parte de Espadas como labios, que contiene los poemas más célebres de esa obra, entre ellos, «El vals». La primera parte estaba dedicada a Dámaso Alonso; la tercera, a Manuel Altolaguirre; la cuarta, a Luis Cernuda.

Dos fotografías abren y cierran el 27, aunque el grupo había entrado pronto en la imprescindible compilación de Gerardo Diego Poesía española. Antología, 1915-1931. La primera, en el Ateneo de Sevilla. Diciembre de $1927^{26}$. Allí están celebrando el centenario de Góngora. Vemos a Alberti, Lorca, Chabás, Bacarisse, Jorge Guillén, Bergamín, Dámaso Alonso y Gerardo Diego, entre otros. La fotografía en la que aparecen por última vez los miembros del 27 se tomó el 20 de abril de 1936. El día 1 de ese mes había salido la primera edición de La realidad y el deseo, de Luis Cernuda, publicada por José Bergamín. El día 19, se celebra un banquete de homenaje a Cernuda en un restaurante madrileño ${ }^{27}$ que todavía permanece. Los avatares políticos de la República no han hecho mella en el grupo. Federico García Lorca pronuncia su último brindis. Asisten Salinas, Alberti, María Teresa León, Pablo Neruda, Bergamín, Altolaguirre, Aleixandre y muchos más. Oigamos a Lorca:

Entre todas las voces de la actual poesía, llama y muerte en Aleixandre, ala inmensa en Alberti, lirio tierno en Moreno Villa, torrente andino en Pablo Neruda, voz doméstica entrañable en Salinas, agua oscura de gruta en Guillén, ternura y llanto en Altolaguirre, por citar poetas distintos, la voz de Luis Cernuda erguida suena original, sin alambradas ni fosos para defender su turbadora sinceridad y belleza ${ }^{28}$.

La guerra del 36 no solo segó vidas humanas. Arrasó también la casa de Vicente Aleixandre en el Parque Metropolitano de Madrid. Se perdieron muchas cosas. Pero se salvó un ejemplar del Llanto por la muerte de Ignacio Sánchez Mejías, dedicado por Lorca a Aleixandre.

${ }^{24}$ Armero, Gonzalo y Fernández-Montesinos, Manuel (1996): Álbum fotográfico de Federico García Lorca, Granada, Colección Huerta de San Vicente, n. ${ }^{\circ}$ 3, fotografía 75.

${ }^{25}$ García lorca, Federico (1997): Obras Completas III, Prosa, Barcelona, Círculo de Lectores, pp. 454-457.

${ }^{26}$ La instantánea fue tomada por Pepín Bello, cuyas ideas tanto influyeron en Lorca y Dalí.

27 Actualmente el restaurante se llama «Los Galayos», cerca de la Plaza Mayor, en la calle Botoneras. El homenaje se publicó en El Sol (21-IV-1936).

${ }_{28}$ García Lorca, Federico (1997): Obras Completas III, Prosa, Barcelona, Círculo de Lectores, p. 289. 
Y ¿qué pensaba Dámaso Alonso? El sabio, la deslumbrante memoria del 27. Afortunadamente, sus libros y sus manuscritos han llegado a buen puerto. No han padecido tanto como los de Lorca, ni están desubicados, como los de Aleixandre. El traslado de la biblioteca de Dámaso Alonso a la Real Academia Española es un hecho importantísimo no solo para el estudio del autor sino del 27. Además, la edición facsímil de Vida y $\mathrm{Obra}^{29}$, nos acerca a su creación más íntima, llena de rectificaciones y anotaciones. Se trata de un cuaderno de 72 cuartillas, que termina así: «No debería, pues, haber empleado el título «Vida y Obra», sino, todo lo más, «Vida y media obra». En el cuaderno (p.17) se lee: «En 1925 me llegó la amistad de Gerardo Diego; y enseguida la de Jorge Guillén [...] Muy poco después comenzó mi [tacha cariño y escribe encima: «conocimiento y [ahora tacha amistad] cariño con Federico García Lorca».

Unas pocas líneas más adelante (p.18) pone: «Ese mismo año [1927], hacia diciembre, fuimos a Sevilla [...] Pedro Salinas no pudo ir, por su quehacer, Vicente Aleixandre tampoco, por su malestar». Pero no se ha divulgado un dato importante. En junio de 1929 viaja con su mujer a Estados Unidos. Casi por los mismos días que Lorca. Y confiesa: «seguí la gran bajada de la bolsa norteamericana» (p.19). Dámaso recuerda en su cuaderno que se veía mucho con Lorca, que iba muchos domingos en compañía con José Antonio Rubio a comer con él y su mujer. Y añade: «Federico empezó a escribir allí poemas que fueron a formar gran parte del libro Poeta en Nueva York. Nos los leía a José Antonio Rubio y a mí, al día siguiente de haberlos redactado». Retengamos esta observación que en parte explicará el huracán poético de Hijos de la ira, aparecido en 1944.

La desaparición de Lorca le inspira a Dámaso el poema «A un poeta muerto», escrito en Valencia durante la guerra (hacia 1936 o 1937), recogido luego en Oscura noticia, aunque su autor matiza: «Sin que se refiera exactamente a él». El paralelismo entre «A un poeta muerto» y «El enterrado» es evidente. Y apostilla en Vida y Obra (p. 24): «Más tarde en 1940, cuando fui una vez a Valencia, hice un poema «Entre Alfacar o Víznar», donde se suponía sepultado a Federico». El poema figura también en Oscura noticia, con su título definitivo «La fuente grande o de las lágrimas (entre Alfacar o Víznar). Lleva una cita de Lorca: «Mi corazón reposa junto a la fuente fría».

En fin, podríamos seguir este recorrido de la amistad inalterable y creciente de los tres maestros. He preferido hablar solo hasta 1936, porque la guerra lo rompe todo, todo lo trasmuta. Pero conviene señalar que después de la desaparición de Lorca, Aleixandre y Dámaso Alonso se han publicado y se vienen publicando una serie de cartas y documentos que dan nueva luz sobre lo que fue el 27. El Epistolario de Vicente Aleixandre a Juan Guerrero y a Jorge Guillén ${ }^{30}$, por ejemplo, «ha supuesto -en palabras de Morelli- una importante e inesperada aportación al ofrecernos la posibilidad de acceder a nuevos e interesantes datos, que amplían el conocimiento de las relaciones concernientes al grupo generacional del 27».

Me gustaría terminar con una alusión a Álbum, el cuaderno en el que escribieron los tres integrantes del grupo de Las Navas, Aleixandre, Dámaso Alonso y Ramón Álvarez Serrano, llamado Preludio de la Generación del 27, y que recoge composiciones que van

\footnotetext{
29 Alonso, Dámaso (1997): Vida y Obra (Edición facsímil), Madrid, Caballo Griego para la Poesía.

${ }_{30}$ Aleixandre, Vicente (1998): Epistolario de Vicente Aleixandre a Juan Guerrero y Jorge Guillén, Madrid, Caballo Griego para la Poesía-Fundación Generación del 27.
} 
de 1918 a 1924, aunque en 1922 entre en declive. Álbum no solo contiene buena parte de la prehistoria poética de Vicente y Dámaso, sino que es fundamental para ver la reacción de estos jóvenes ante la vanguardia, y ante los dos maestros consagrados: Antonio Machado y Juan Ramón Jiménez.

La edición de Álbum, llevada a cabo por Alejandro Duque Amusco y María JesúsVelo $^{31}$, se abre, por expreso deseo de Dámaso con un poema suyo dedicado a Vicente, a quien años atrás dedicó estos versos:

Vicentico, mi Vicente,

hijito, te dije yo

que esta zorra de la vida

nos la jugaba a los dos.

Luego, en 1985, Dámaso compone «Mi amistad con Vicente Aleixandre», donde leemos:

Año mil novecientos diez y siete:

Vicente y yo, qué gozo este verano,

en Navas del Marqués. Pronto, ¡qué amigos!

Primera vez en aquel día juntos;

después, toda la vida para siempre.

Vicente ya había desaparecido, pero Dámaso no lo percibe así. Es como si del árbol, solo hubieran caído las hojas. Como Federico, cuando dedica a Vicente su «Vals en las ramas»:

Cayó una hoja.

$\mathrm{Y}$ dos.

$\mathrm{Y}$ tres.

Por la luna nadaba un pez.

El agua duerme una hora

y el mar blanco duerme cien

${ }^{31}$ Aleixandre, Vicente (1993), Alonso, Dámaso y otros: Álbum, Versos de juventud, Barcelona, Tusquets, 